\title{
IDENTIDADE E ALTERIDADE ENTRE OS ESE EJJA DA BOLÍVIA SETENTRIONAL *
}

Isabella Lepri

Este artigo trata da construção da identidade em uma sociedade da Amazônia boliviana, uma identidade que se constrói através da relação com outros. Mais precisamente, explora a atitude ambivalente dos Ese Ejja perante os bolivianos mestizos e brancos (doravante designados simplesmente como "bolivianos"). Essa atitude é caracterizada por um misto de medo e admiração, de evitação e, ao mesmo tempo, emulação, com um entendimento subjacente de que os Ese Ejja estão se tornando bolivianos. A análise da relação com os bolivianos nos ajuda a compreender as idéias dos Ese Ejja sobre identidade e sua transformabilidade. Com o termo identidade refiro-me a quem os Ese Ejja pensam que são quando referem-se a si mesmos como "nós", seja na qualidade de grupo ou de membros individuais desse grupo — trata-se, em outras palavras, de sua "auto-imagem" (ver Caiuby Novaes 1997).

"Identidade" é uma categoria analítica problemática (ver Sökefeld 1999), e o termo "auto-imagem", tal como discutido por Sylvia Caiuby Novaes, reflete mais apropriadamente o fenômeno aqui descrito. Neste artigo, não discuto a identidade como imagem adotada por membros de um grupo (minoritário) tendo em vista fins políticos - como é o caso da "identidade étnica", da "identidade racial" ou da "identidade cultural" — e a obtenção de visibilidade ou reconhecimento. Nesse sentido, os Ese Ejja estão sendo lentamente introduzidos aos discursos de indianidade e da política de identidade, mas esse é um assunto que não nos concerne aqui. O que descrevo é o modo como a percepção e a representação que os Ese Ejja têm de si próprios mudam à medida que eles entram em contato com diferentes Outros. A relação com o Outro é um tema central da etnografia amazônica e é uma questão crucial na análise das situações de contato em geral. 
Para explorar tais assuntos, convém ter em mente a noção de "jogo de espelhos", desenvolvida por Caiuby Novaes (1997) com relação aos Bororo do Brasil Central. Segundo essa autora, a auto-imagem é determinada pelo modo segundo o qual um grupo ou indivíduo percebe a si mesmo como objeto da percepção de um outro. O caso dos Ese Ejja dá apoio à idéia de que a auto-imagem é múltipla, relacional e mutável, tanto do ponto de vista do observador quanto do indígena. É relevante o fato de que essa noção de transformabilidade coexiste com uma idéia de facticidade e finitude, como quando se diz que a pessoa já nasce Ese Ejja ou boliviana. Em outra ocasião, mostrei de que modo essas idéias podem coexistir no contexto do parentesco (Lepri 2003); aqui, estendo o argumento para explicar que, embora os Ese Ejja afirmem insistentemente que a pessoa nasce Ese Ejja, eles também se vêem em processo de tornarem-se outra coisa, a saber, bolivianos ${ }^{1}$.

Minha etnografia ilustra as práticas discursivas diárias nas quais e através das quais os Ese Ejja reproduzem e transformam as noções sobre quem são. Essas noções são múltiplas, por vezes contraditórias, e variam segundo os encontros com os diversos Outros, aí incluídos os bolivianos e os outros povos indígenas, mas também os gringos - isto é, missionários e antropólogos. Em nome da clareza, focalizarei neste artigo os dois primeiros, uma vez que as relações entre os Ese Ejja e os gringos exigem discussão à parte (ver Lepri 2003).

Por fim, sugiro que as atitudes dos Ese Ejja com relação aos bolivianos podem ser lidas em termos sociocosmológicos como um exemplo da lógica do "tornar-se outro", descrita por Eduardo Viveiros de Castro como característica das sociedades sem centro, sociedades que encontram sua realização através da incorporação - canibalística ou outra - de estranhos (Viveiros de Castro 1992). Essa lógica é coerente com as noções ese ejja da história como deslocamento espaço-temporal que vai da "selvageria" à "civilização".

O objetivo do artigo é oferecer um relato etnográfico da formação e transformação da identidade de um grupo no encontro com outro, e enfatizar o caráter relacional e mutável da identidade, empregando noções e percepções - indígenas e exteriores - para associar tal processo às idéias indígenas sobre a história. Objetivo adicional é o de descrever uma sociedade empenhada em um relacionamento em curso com os grupos vizinhos, e não em isolamento, retirando-a assim do contexto etnográfico específico. As sociedades amazônicas são com freqüência apresentadas como se fossem mônadas com fronteiras mais ou menos rígidas. Pode-se afirmar que isso se deve em grande parte à natureza dos discursos com que os 
antropólogos se depararam no campo, discursos que sugeriram uma predisposição fortemente etnocêntrica por parte dos informantes. É com essa questão que lidarei agora, iniciando a discussão.

\section{Humanos de verdade}

As atitudes aparentemente ambíguas dos Ese Ejja para com os bolivianos estão condensadas na afirmação recorrente de que eles mesmos estão se tornando bolivianos, e na atribuição de qualidades desejáveis a esses estranhos perigosos. É opinião corrente que muitos povos das terras baixas da América do Sul são altamente etnocêntricos e, em apoio a isto, afirma-se que eles se consideram "gente de verdade". Segundo Lévi-Strauss:

A humanidade cessa nas fronteiras [...] do grupo lingüístico [...] a tal ponto que um grande número de populações ditas primitivas se autodesignam com um nome que significa "os homens" (ou às vezes [...] os "bons", os "excelentes", os "completos"), implicando assim que outr[o]s [...] grupos [...] não participam das virtudes ou mesmo da natureza humana (1977:329 [1976:334]).

Por toda a Amazônia, abundam afirmações desse tipo (ver, por exemplo, Gow 1991; Gray 1996; Hugh-Jones 1978; McCallum 1997; Rosengren 2003; Siskind 1973; Taylor, no prelo; Townsley 1987; Turner 1993; Viveiros de Castro 1992).

O uso dos termos "humano" e "gente" para traduzir autodesignações indígenas é problemático por duas razões. Primeiro, por assumir uma correspondência entre os conceitos indígenas de humanidade e os do antropólogo, sobre a qual Viveiros de Castro lança dúvidas com a discussão da humanidade como "posição de sujeito" (1998:476 [1996:125]) na filosofia perspectivista dos povos amazônicos. Como ele observa, "as palavras ameríndias que se costumam traduzir por 'ser humano' [...] funcionam (pragmática quando não sintaticamente) menos como substantivos que como pronomes", remetendo a nós e não a gente como sinônimo de 'pessoa, ser humano', o que dá conta da variabilidade das categorias indígenas de identidade. Ser humano, nesse sentido, é ser o locus de uma perspectiva e de uma intencionalidade, e não um membro da espécie humana. Em segundo lugar, o uso da palavra "humano", carregada de conotações essencialistas, é especialmente enganador, pois a condição a que ela se refere é melhor entendida em termos de comportamento do que de essência. Por toda a Amazônia, a identidade é considerada em grande parte processual, e ser huni kuin 
(Kaxinawa), bide (Araweté) ou piro (Piro) está ligado, em um sentido bem relevante, ao comportamento. Conseqüentemente, qualquer um pode, através de suas ações, tornar-se um autêntico Piro, Kaxinawa e assim por diante.

Caiuby Novaes mostra que a autodesignação bororo (boe) "pode ser traduzida como pessoa, ser humano" e acrescenta que "nesse sentido todos os não-boe são deixados de fora dessa categoria" (1997:51). No entanto, ela ressalta que, embora os Bororo possam ser etnocêntricos no nível de seus valores, isso não impede que avaliem as "realizações e fracassos" de outros segmentos populacionais e que tratem-nos como humanos (1997:51). Essas avaliações produzem ajustamentos constantes em sua auto-imagem, que eles vêem refletida nos espelhos que são os Outros.

O caso bororo apresentado por Caiuby Novaes mostra que a identidade, entendida como auto-imagem, é sempre relacional e transformada por relações com qualquer Outro que projete uma imagem diferente de volta para o sujeito original. É com essa discussão em mente que me proponho abordar o material ese ejja.

\section{Pessoas que não são gente}

Os Ese Ejja também são conhecidos na literatura como Chama, na Bolívia, e Huarayos, no Peru. Tais nomes são considerados pejorativos pelos próprios Ese Ejja, mas são amplamente usados pelos mestizos e brancos.

A aldeia de Portachuelo, onde esta pesquisa foi realizada, situa-se na margem esquerda do baixo Beni. Tem cerca de 400 habitantes, divididos em três núcleos ao longo do rio: Portachuelo Alto, Medio e Bajo ${ }^{2}$. Portachuelo Alto e Portachuelo Bajo são ocupados pelos Ese Ejja, enquanto em Portachuelo Medio os habitantes são Tacana. Embora pertençam à mesma família lingüística, Ese Ejja e Tacana não reconhecem entre si nenhuma relação, salvo uma longa história de conflito. No entanto, vivem hoje lado a lado de modo relativamente pacífico, com intercasamentos ocasionais.

Os Ese Ejja têm uma economia mista de caça, pesca e coleta, com alguma horticultura; viajam a Riberalta, cidade que centraliza o comércio regional (distante cerca de oito a doze horas rio abaixo, em barco a motor), para vender bananas e esteiras de folhas de palmeira, e comprar arroz, óleo, açúcar, sal e sabão. Assim, os espaços significativos para as pessoas de Portachuelo são a aldeia, a floresta, o rio e suas praias, e a cidade.

Um pouco mais de um mês após minha chegada em Portachuelo, certa manhã, de pé junto ao rio, vi uma canoa chegando rio abaixo; voltei-me para uma menina Ese Ejja que estava por perto e lhe disse: "Ese Ejja bisheje 
yacaje" (Ese Ejja está/estão descendo o rio de canoa). A menina respondeu em espanhol: "No es Ese Ejja, es gente!" Desnecessário dizer que fui surpreendida pela afirmação (que eu entendi como negação de que os Ese Ejja fossem gente, humanos). Logo vim a saber que os Ese Ejja referem-se aos bolivianos hispanofalantes como "gente" e, em ese ejja, como "dejja" ou "dejja nei". Nei significa 'muito' (como em muito bonito, muito frio), mas também 'de verdade', 'real', 'autêntico'. Ser dejja está associado, em primeiro lugar, com o domínio do espanhol - e com um conjunto de práticas que descreverei adiante - mas também implica uma conotação 'racial', na medida em que pessoas de pele clara são mais prontamente identificadas como "ninco" (do espanhol gringo), uma categoria distinta de dejja.

Gente, além do significado usual, também carrega, no idioma espanhol local, um sentido de fidalguia e de respeitabilidade, especialmente quando usado em expressões como gente buena, 'pessoa boa, respeitável' ou gente decente, que designa os bolivianos instruídos ou da classe alta. Para os bolivianos, dizer que os índios não são gente não significa necessariamente que não são humanos; mas isso certamente não anula o fato de que, historicamente, indígenas foram representados e tratados como não-humanos ou sub-humanos. Até hoje, as pessoas da cidade referem-se aos chama empregando metáforas animais. Em Riberalta, uma idosa que possuíra uma grande hacienda me disse: "Aqueles chamitas vinham sempre à fazenda, andando devagar com suas patinhas ("patitas"), mas eram tão ariscos como agora, quando você os vê na cidade". O termo arisco é usado para descrever animais selvagens que fogem e se escondem. Em outra ocasião, um conhecido descreveu os Ese Ejja como "daniños", termo empregado em referência a animais nocivos.

Quando perguntei a Peno, um dos mais antigos habitantes de Portachuelo, qual a diferença entre Ese Ejja e dejja, ele respondeu que os Ese Ejja não comiam alimentos cozidos na água ou no vapor - apenas assando-os diretamente ao fogo - nem comiam arroz, mandioca ou tomates. Quando retruquei que, na verdade, eles comiam tais alimentos, Peno respondeu: "Sim, eles comem arroz, mas só esses novos, os mais jovens, que já são bem civilizados. Mas antes eles não conheciam o arroz, nem cebolas, nada. Os dejja vivem bem, comem bem, comidas bem preparadas. É assim." Esse discurso é reproduzido pelos mais jovens, na intenção de afastá-los dos "antigos" que, segundo sua definição, não usam roupas, não conhecem comida de verdade e não usam sal.

Quando perguntei se um Ese Ejja poderia se tornar dejja, Peno afirmou: "É claro. Pode sim. Aprendendo tudo direito. Então, gente não dirá que ele é chama" - a designação pejorativa mencionada acima. "Esses 
homens mais jovens, eles são gente", continuou, "não são mais como os de antes. Antes, pensavam que os chama eram como animais, mas já não é assim." É interessante que ele tenha se referido à percepção dos de fora, que associavam os Ese Ejja com animais. Note-se que entre os Ese Ejja mais jovens, isto é, os "quase dejja", são predominantemente homens aqueles que mais rapidamente assimilam costumes bolivianos em suas práticas, ao passo que as mulheres são consideradas mais conservadoras.

Devo ressaltar que, apesar do reconhecimento do poder transformativo do comportamento, há também um sentido muito claro de que a pessoa já nasce dejja ou Ese Ejja. Em outras oportunidades (Lepri 2003, 2005b), descrevi de que modo, para os Ese Ejja, a identidade é tanto algo herdado quanto processual, o que é coerente com a noção de que embora dejja e Ese Ejja sejam inteiramente distintos, os Ese Ejja podem, com o tempo, tornar-se dejja. A coexistência de noções do que é dado e do que se transforma permite alguma negociação no jogo identitário.

É certo que, a princípio, fiquei surpresa ao descobrir que os Ese Ejja pudessem dizer de si próprios que não são "gente mesmo", mas posteriormente comecei a suspeitar que esta poderia simplesmente ser uma afirmação de diferença: "os dejja são o que não somos", "eles são pia", isto é, outros. Como me disse um homem chamado Santo: "Dejja nei são aqueles que vivem em Riberalta, os misturados. Esses são dejja nei. Dejja nei é como... boliviano." No entanto, um exame mais cuidadoso do significado da palavra dejja exige que reconsideremos a questão. Dejja também significa 'homem' ou, mais precisamente, 'homem adulto Ese Ejja'. Mais comumente, as palavras usadas para homem são: cui-iji, que significa literalmente 'com pênis', e yahue, que também significa 'marido'; essas palavras não se referem apenas aos Ese Ejja do sexo masculino, mas também a animais e espíritos, ao passo que dejja refere-se exclusivamente a humanos. Este termo é comumente empregado em nomes pessoais masculinos, conjugados com adjetivos, como em Dejja Oshie, 'Homem Branco', Dejja Ai, 'Homem Grande', Dejja O'o, 'Homem Alto'; e embora outros nomes - como os tomados de animais - possam ser usados para ambos os sexos, uma mulher nunca seria chamada de Dejja. Isso é interessante com respeito ao fato, acima mencionado, de que os homens, mais que as mulheres, são considerados 'quase dejja'. Ademais, o termo dejja é também empregado em expressões que descrevem homens, como quea-dejja-til, '(ele é) um homem velho', e quae-dejja-tai, '(ele é) um homem avarento'. E além disso, conforme ouvi de missionários evangélicos, o nome Ese Ejja seria uma contração da expressão ese dejja ('nós, homens'). Segundo estes últimos, este seria um sinal claro de que os Ese Ejja consideravam-se um povo de homens, valorizando-os mais do que 
as mulheres. Isso me parece mais coerente com o fundamentalismo cristão do que com a ideologia indígena, pois ainda que a etimologia esteja correta, o juízo de valor a ela vinculado é certamente equivocado, uma vez que os Ese Ejja não atribuem aos homens status mais elevado do que às mulheres, e que homens e mulheres fazem coisas diferentes, sendo igualmente necessários e valorizados (ver McCallum 1990, para uma discussão de 'humanidade' e gênero). Seja como for, os significados e usos da palavra dejja confirmaram minha impressão de que os Ese Ejja de fato negavam algo a si mesmos: se não a qualidade humana, ao menos algumas qualidades associadas aos homens adultos, como força e bravura, que eles atribuem aos seus (antigos) inimigos.

O fato de que os Ese Ejja considerem-se inferiores aos bolivianos é constantemente reafirmado pelas próprias pessoas, quando dizem ser ignorantes, atrasadas, covardes, sujas e pobres, enquanto os bolivianos são educados, limpos e possuem "coisas". Assim, por exemplo, ao ver fotografias de Ino, que me acompanhara em uma viagem ao Peru, amigos dela observaram que ela parecia dejja pelo cuidado corporal que ostentava (para a ocasião, ela havia feito também um permanente em seu cabelo). Em outra ocasião, algumas meninas entraram em minha casa e, olhando para meus poucos pertences, riram e disseram que eu não era dejja porque nada possuía.

A seguir, abordarei as implicações deste discurso: o modo como os de fora consideram os Ese Ejja sub-humanos, tratando-os como tais; o modo como os próprios Ese Ejja podem ter internalizado essa mensagem e, por último, o modo como essa forma de relacionar-se com o Outro se adequa às idéias sociocosmológicas do "tornar-se outro" e com as idéias ese ejja sobre a história.

Se os Ese Ejja estão afirmando sua própria inferioridade e vêem a si próprios como parte do processo de tornarem-se bolivianos, por que isso se dá? Poderíamos imaginar que, depois de séculos de exploração por estrangeiros, eles tenham absorvido o discurso colonial de sua própria inferioridade, assim como a ideologia nacionalista de resgate da selvageria através da miscigenação. Em segundo lugar, há razões políticas e econômicas: assemelhar-se aos bolivianos - claramente mais ricos e mais poderosos - poderia trazer acesso a bens desejáveis, o que configuraria motivo suficiente para querer "ser como eles". Mas a atração pela riqueza e poder de outros não leva necessariamente a desejar transformar-se: os Ese Ejja poderiam, a seu próprio modo, querer obter os poderes econômicos e políticos dos bolivianos, como no caso dos Kaxinawa, segundo McCallum (1997); ou poderiam expressar a própria identidade, superando os bolivianos em seu jogo, conforme relata Anne-Christine Taylor (no prelo), a respeito dos Achuar. Sem dú- 
vida, a retórica colonial e nacionalista - assim como fatores políticos e econômicos - tem sido elemento significativo, e as afirmações de inferioridade por parte dos Ese Ejja também são parte de uma estratégia de evitar envolvimento na sociedade nacional, considerada perigosa. Além do mais, é possível uma explicação sociocosmológica, a saber: que os Ese Ejja vêem os bolivianos, seus inimigos, como um destino, e o que aparece como autodepreciação é, de fato, um sinal da lógica do "tornar-se outro", descrita por Viveiros de Castro para os Araweté (1992), segundo a qual as pessoas se realizam incorporando a alteridade e, com isso, superando-a, conforme discutirei. Isso é coerente com a compreensão que têm os Ese Ejja da história como movimento espaço-temporal da 'selvageria' dos ancestrais para a 'civilização' dos jovens, que são considerados quase bolivianos — devendo-se aqui entender "selvageria" e "civilização" como termos ese ejja. Discutirei adiante que esse movimento no tempo corresponde à migração no espaço: da floresta e dos afluentes rio acima para os trechos mais abaixo, onde as cidades foram construídas. Essa migração é atribuída aos ancestrais, mas também reaparece em histórias pessoais (Lepri 2005a:129).

Nas seções seguintes, descrevo de que modo os Ese Ejja se comportam como - e, portanto, se transformam em - dejja quando estão entre eles, e como tornam-se "selvagens" quando defrontados com bolivianos. Essa observação corrobora o fato de que ser "gente de verdade" não tem a ver com uma afirmação absoluta, mas depende da perspectiva e posição relativa, sendo parte de um processo em andamento.

\section{Sendo dejja}

As sociedades amazônicas, de modo geral, estão centradas na construção de pessoas pela intervenção em seus corpos, desde a alimentação e outros cuidados, passando pela pintura, escarificação e perfuração, até a reclusão. E como foi ressaltado, "uma consideração do lugar do corpo humano na visão que as sociedades indígenas [da Amazônia] fazem de sim mesmas [é um dos] caminhos básicos para uma compreensão adequada da organização social e cosmologia destas sociedades" (Seeger et alii 1979:3). Entre os Ese Ejja, essa transformabilidade pelas práticas corporais fica manifesta na idéia de que ao comerem, cozinharem, vestirem, casarem e jogarem como os bolivianos, também estariam tornando-se bolivianos.

Nos últimos cem anos, os Ese Ejja adotaram o estilo das moradias, roupas, armas, alimentos, esportes e, mesmo, da terminologia de parentesco dos bolivianos (ver Lepri 2005b) e, conforme mostrei, os mais velhos 
consideram que os jovens são quase dejja. Muitas pessoas se opõem a casamentos com dejja, mas os jovens se dizem favoráveis a essas uniões - embora muitos casem com primos cruzados - e até alguns dentre os mais velhos sustentam que os dejja são bons trabalhadores, que dão bons genros, enquanto os jovens Ese Ejja são preguiçosos e só estão interessados em jogar futebol (ver Lepri 2003:96).

Minha descrição se inicia com o lar da família Monje, em Portachuelo Bajo, com a qual morei durante os nove primeiros meses de trabalho de campo, mas se estende a outros indivíduos e famílias de Bajo assim como de Alto. Os Monje faziam três refeições por dia, sentavam-se em bancos em torno da mesa e cada um tinha um prato, uma colher e uma caneca. Em outras casas, o consumo de alimentos era menos sujeito a regras e as pessoas tendiam a congregar-se após uma expedição bem-sucedida de caça ou pesca. Quando não, as mulheres simplesmente assavam bananas ou cozinhavam arroz; os membros da família servindo-se e indo comer do lado de fora, onde conversavam com vizinhos ou passantes. Na ausência de carne ou peixe, os Monje tentavam produzir pratos elaborados, preparando a massa do macarrão - comida dejja - e cozinhando-a como substituto da carne (sem dúvida, isso em parte deve ter sido estimulado por minha presença).

Sempre que eu saía para Riberalta, Ino, a mãe, pedia-me que comprasse queijo, alimento considerado repulsivo por muitos Ese Ejja devido a seu forte odor. Aos cozidos e sopas ela sempre acrescentava temperos salgados (também adquiridos no mercado), o que dava o mesmo gosto a tudo, do bagre à carne de veado e da carne de macaco ao jacaré. Ela usava cebolas e cominho, e preparava saladas com tomates e pepinos - considerados comida dejja - que o marido começara a cultivar em sua nova horta.

Segundo a mesma lógica, alguns alimentos são considerados marcadores fortes da identidade Ese Ejja, em oposição ao que seria caracteristicamente dejja. Bananas são associadas à condição Ese Ejja, em contraste com o arroz; elas eram consumidas diariamente, assadas, cozidas, fritas, amassadas, raladas, verdes ou maduras, e a partir delas também costumava-se preparar uma bebida, chamada epohui. Alguém que não comesse muitas bananas e preferisse arroz era chamado dejja-jayojja, 'semelhante a dejja'. Os ovos de certo bagre, que os Outros não comem mas que os Ese Ejja muito apreciam, também são considerados um prato ese ejja.

Para o almoço, Ino insistia em que comêssemos ao meio-dia, ainda que tivesse apenas uma vaga idéia da hora. Isso também fazia parte de sua semelhança aos bolivianos. A maioria dos Ese Ejja não tinha relógios e, entre os que os usavam, alguns o faziam apenas por gosto, sem nem mesmo saber como funcionavam. Ao dizer as horas, faziam-no com uma aproxima- 
ção de, no mínimo, meia hora (para mais ou para menos) em relação à hora do relógio - o que, em Portachuelo, não fazia grande diferença. Mas Ino sempre me perguntava as horas e, se fosse perto do meio-dia, ela costumava dizer: "É tempo de preparar o almoço." Cada uma dessas ações - sentar em volta da mesa, temperar a comida, comer queijo e saladas, fazer refeições regulares em horários mais ou menos fixos e repetidos cotidianamente criava a impressão de maior semelhança com os dejja.

Entre os costumes dejja adotados pelos Ese Ejja, o futebol tem lugar de destaque. Ele é um exemplo eloqüente de que os Ese Ejja querem ser como os dejja - mas em seus próprios termos — ou seja, imitando-os seletivamente e excluindo comportamentos que contradigam sua própria ética.

Jogos informais se realizam diariamente, com a participação de homens e mulheres, em preparação para os jogos formais que acontecem semanalmente. Os jogos oficiais entre as aldeias começam com um convite por escrito, feito pelo presidente de um clube de futebol a outro. As cartas de convite, redigidas em espanhol, têm tom bastante formal e estipulam a data, horário e local do encontro; são enviadas com muitos dias de antecedência e devem receber resposta oral ou escrita. As equipes usam uniformes, geralmente fornecidos por políticos locais em busca de votos. Várias vezes por ano, realizam-se torneios entre as equipes oficiais: Os Fortes, de Portachuelo Alto, Bolívar, de Portachuelo Bajo - ambos, nomes tomados de times da capital, La Paz - e também Horizonte, de Portachuelo Medio, e o time dos professores da escola. Os vencedores dos torneios ganham troféus que - ciúmes à parte - todos podem admirar: em Portachuelo Bajo os troféus ficam na velha igreja onde se realizam as reuniões e que também abriga o aparelho de televisão. Em Portachuelo Alto, os troféus são guardados em uma casa de tijolos, de construção recente, parte de um projeto de processamento de arroz que não chegou a se completar. A joeiradora nunca chegou, mas do lado de fora da construção - que é usada como local de reuniões, depósito de materiais e para abrigar um pequeno gerador elétrico - chama atenção uma grande placa de cores fortes, com o nome do presidente do país e o lema: "Trabalhando juntos pelo futuro da Bolívia".

Dentro de campo, observei que há grande competitividade por parte de homens e mulheres, que levavam, todos, o jogo extremamente a sério. Eles sem dúvida jogavam para ganhar, mas a busca da vitória era contrabalançada pelo desejo de viver pacificamente - pois as vitórias muito flagrantes sempre causam irritação, contrariedade, e não raro degeneram em lutas físicas. As pessoas repetiam a maioria dos gestos e posturas que haviam visto nos jogadores de futebol em Riberalta ou, ocasionalmente, na televisão. Eles imitavam as poses dos goleiros, as expressões da defesa ao formar uma 
barreira ou interceptar um ataque, e os movimentos dos bandeirinhas e do juiz. Isso, porém, com uma notável exceção: após o gol não havia comemoração - nem saltos, abraços, socos no ar; nem cumprimentos à torcida. Os jogadores simplesmente reiniciavam o jogo, com expressão severa. O conflito entre o desejo de vencer e o desejo de empatar foi-me confirmado pelas atitudes das pessoas com relação ao placar final. Não há dúvida de que cada time tentava fazer mais gols do que o outro, mas sempre que eu perguntava o placar, recebia invariavelmente como resposta o número de gols necessários para igualar o marcador. Não se tratava, porém, de um inequívoco desejo de que não houvesse vencedores: sem que se deixasse de aspirar intensamente à vitória, um empate era mais aceitável por eliminar as possibilidades de violência, ameaças de feitiços e brigas. E isso é coerente com a tendência observada de se evitar o confronto direto (ver Lepri 2005a).

\section{Face a face com os bolivianos}

Até aqui, descrevi como os Ese Ejja adotaram vários modos dejja de agir, razão pela qual afirmam que os jovens são "quase dejja". Nesta seção, passo a examinar de que modo, ao se defrontarem com os dejja, os Ese Ejja deixam de ser como os bolivianos e se enquadram na imagem estereotipada do "selvagem", pela qual são conhecidos entre os estrangeiros. Nesses encontros, a imagem ese ejja é modificada, bem como sua percepção dos bolivianos, que deixam de ser vistos como modelos do que os Ese Ejja deveriam tornar-se, sendo a eles atribuída uma série de qualidades negativas, em contraste com os valores mantidos pelos próprios Ese Ejja. Essa inflexão é coerente com as opiniões contraditórias expressas pela percepção de qualidades desejáveis de dejja e o temor e desapreço por eles. Essa contradição surge nas conversas sobre a vida em Portachuelo em contraste com a vida em Riberalta.

Em Portachuelo vive-se queabihui, feliz ou em paz, porque não falta comida - pois sempre se pode ir caçar, pescar ou colher frutos na floresta mas também porque se está cercado de parentes que ajudam-se ou sustentam-se mutuamente; não há queatai emimijji (maledicência, mexerico), nem roubos. As pessoas também salientam que em Portachuelo não há o perigo representado pelos bolivianos agressivos: não há nem policiais nem soldados - chamados dejja mase, 'gente má' — nem há maleantes, palavra espanhola para 'criminosos', dos quais se diz que a cidade está repleta. O único lugar seguro na cidade é a Missão Evangélica Suíça, onde os Ese Ejja recebem tratamento médico e assistem a 
alguns cursos bíblicos. Em todos os demais lugares, eles correm o risco de serem destratados e de passar fome. Os poucos Ese Ejja que residem semi-permanentemente em Riberalta, vivem nas margens barrentas do rio "comendo porcaria", conforme Ino sempre dizia. São proscritos pelo resto do grupo e mesmo por seus parentes. É como se parcamente existissem, conforme tive a oportunidade de inferir: tendo sido informada de que não havia Ese Ejja em Riberalta, descobri posteriormente que muitos tinham lá parentes dos quais, no entanto, se envergonhavam.

Em Portachuelo, a interação entre Ese Ejja e dejja se dá através dos professores de escola e dos Tacana de Portachuelo Medio (uma vez que o status dos Tacana oscila entre dejja e indigena - ver adiante). Os professores têm pouco contato com a maioria dos adultos. Estes relutam em ir às reuniões de pais e têm de ser forçados a participar do trabalho anual, necessário para tornar habitáveis as residências dos professores que, por sua vez, reclamam da disposição pouco amigável dos chama e repetem que são "preguiçosos", "selvagens" e "maus"; dizem ainda que não têm vontade de melhorar ("adelantarse") e que são egoístas em relação aos filhos, tirando-os da escola na estação seca, quando se mudam para as praias do rio para pescar e procurar ovos de tartaruga. No entanto, ainda que vejam sua tarefa como um trabalho de Sísifo, insistem apesar de tudo em tentar instilar disciplina nos alunos, com exercícios quase marciais.

As pessoas também contam com os professores na obtenção de alguns bens, quando estes últimos atuam como mercadores e vendem produtos alimentares em troca de carne silvestre, peixe ou galinha. Quando isso ocorre, as pessoas se alvoroçam a comprar enlatados, arroz e, especialmente, doces. No entanto, uma vez terminada a corrida comercial, elas reclamam dos professores, dizendo que são avarentos e que vendem os produtos a preços absurdos. O mesmo se dá com os mercadores que percorrem o Beni rio acima e rio abaixo: eles cobram preços exorbitantes, mas vendem produtos muito desejados, como biscoitos, refrigerantes e, por vezes, roupas; além de arroz, sal, açúcar, óleo e álcool.

Ocasiões relativamente freqüentes para contato com os não-Ese Ejja eram os jogos de futebol contra times dejja, quando estes últimos vinham jogar em Portachuelo ou quando os times do local saíam para jogar fora da aldeia. Nessas ocasiões, a interação com os adversários era mantida em um nível mínimo, e as diferenças entre bolivianos e Ese Ejja ficavam patentes. As mais notáveis podiam ser observadas nos espectadores, entre as torcidas. Do lado dejja, havia manifestações excitadas de incentivo, gritos e insultos, especialmente por parte das mulheres, que demonstravam uma impressionante criatividade e atrevimento em suas ofensas a jogadores e 
árbitros. A torcida dos Ese Ejja, por sua vez, permanecia sentada em absoluto silêncio. Durante o jogo, as mães continuavam dedicadas ao cuidado das crianças, como que só parcialmente interessadas no evento. No entanto, os jogos "fora", em outras localidades, provocavam grande agitação, como pude observar em várias ocasiões durante um torneio realizado na comunidade mestiza de Bella Flor, a uma hora de Portachuelo, rio acima. A excitação ia aumentando de manhã, quando as jovens esposas e irmãs dos jogadores preparavam a comida para a viagem, e um animado e numeroso grupo se apertava em um barco e partia para o local do jogo. Próximo ao fim da viagem, no entanto, a animação cedia lugar ao medo e constrangimento de confrontarem-se com os dejja. Ao sair do barco e andar até a aldeia, as pessoas iam ficando mais e mais quietas. Ao chegarem ao campo - uma área gramada junto a uma estrada poeirenta, cercada por algumas casas com teto de sapé - acharam um canto sob uma árvore e aí ficaram, tentando evitar qualquer interação com os dejja. Uma das atrações, nesses eventos, eram os picolés, trazidos por iniciativa de alguns indivíduos do lugar em grandes caixas de isopor. Todos os apreciavam, mas quando me ofereci para comprar alguns a um grupo de meninas, elas se recusaram veementemente a ir comprá-los pessoalmente, dizendo que se sentiam queabicho, 'envergonhadas', porque lá havia queadejjahuiso, 'muitos dejja'.

\section{Tacana}

Como já mencionei, os Tacana são outros dejja que figuram com destaque na experiência cotidiana dos Ese Ejja. Os Tacana de Portachuelo Medio são parte de um grupo indígena reconhecido como tal, mas que nas conversas informais são comumente designados como dejja. No entanto, quando indagados diretamente a respeito, os Ese Ejja costumam afirmar que os 'Tacana são indígenas como nós' (indigenas como nosotros). A linguagem da indianidade deriva do movimento político indígena, do qual os Ese Ejja não participam ativamente, sendo raro envolverem-se em atos de protesto, embora ocasionalmente compareçam a encontros organizados pela organização indígena local. No entanto, a possibilidade dos Tacana serem similares a eles e diferentes dos mestizos também pode ser, ela mesma, uma noção indígena. Daniela Peluso observa que os Ese Ejja no Peru autodesignam-se ese eja nei, 'Ese Ejja verdadeiros', e aos outros povos indígenas chamam ese eja (2003:12-13). Em Portachuelo, disseram-me que aquilo que distinguiria os bolivianos seria o fato de falarem apenas uma língua, ao passo que os povos indígenas falam duas. Poucos falam a língua tacana, 
o que contribui para a sua posição ambígua. Eles também têm laços mais estreitos com a cidade e consideram-se completamente civilizados. Os Tacana têm mais dinheiro do que os Ese Ejja, vestem roupas melhores, têm certidões de nascimento e de casamento e possuem artigos de luxo, como bicicletas. Chamam os Ese Ejja de paisanos, que é um termo pejorativo na região; dizem que os Ese Ejja são selvagens em comparação com eles — que são gente buena, pessoas respeitáveis - e os acusam de práticas bárbaras, a saber, o canibalismo ("saben comer gente").

As relações entre os Ese Ejja e os Tacana vão da evitação à hostilidade aberta, e somente em alguns casos tornam-se amistosas. Ocasionalmente, quando há festas com bebidas, os homens de Portachuelo Medio podem vir a se misturar com homens Ese Ejja, mas tanto estes quanto aqueles preferem beber entre si, e a camaradagem em torno da bebida nunca se estende a atividades como caça ou pesca. Os times de futebol dos Ese Ejja jogam contra times tacana, mas jogadores de um e de outro grupo nunca jogam do mesmo lado. Esses jogos acentuam a usualmente tácita hostilidade, e os Ese Ejja freqüentemente acusam os Tacana de trapacear e provocar brigas.

Há outro tipo de ocasião em que Ese Ejja e Tacana entram em contato: as expedições a Riberalta, quando viajam na mesma embarcação. Nessas viagens, as pessoas dos dois grupos, especialmente as mulheres, não se misturam, dividindo o apertado convés em espaços bem delimitados. $\mathrm{Mu}$ lheres Ese Ejja sentam atrás, com seus bebês e crianças, próximo ao ruidoso motor; dão de mamar, comem, catam piolhos umas às outras, ou simplesmente sentam e olham o vazio. As mulheres tacana sentam-se no meio do convés, fazendo mais ou menos as mesmas coisas, mas também conversam, já que o ruído do motor não é ali tão ensurdecedor; de modo geral, elas parecem bem mais à vontade, seguras o bastante para ocupar o espaço que quiserem, enquanto as Ese Ejja parecem querer desaparecer na escuridão da popa. Os homens, Ese Ejja e Tacana, ficam de pé junto à cana do leme, na proa, ou deitam-se na cobertura da embarcação.

\section{Os Ese Ejja na cidade}

A cidade exerce forte atração sobre os Ese Ejja, especialmente os mais jovens mas, ao mesmo tempo, também provoca medo em função da afirmação reiterada pelos mais velhos de que os dejja - particularmente a polícia - querem matá-los e podem fazê-lo impunemente, "se a pessoa for encontrada sem documentos de identidade" — outro atributo dejja. Eu soube de alguns incidentes do passado recente, em que Ese Ejja foram 
mortos por dejja e certamente a matança de índios era comum no auge da indústria da borracha, quando estes últimos eram vendidos como escravos ou caçados por esporte.

Em Riberalta, os Ese Ejja sobressaem na população mista da cidade, composta de mestizos bolivianos, descendentes de imigrantes japoneses e europeus, e de mercadores e soldados andinos. A imigração para essa região teve seu auge na virada para o século $\mathrm{XX}$, no período mais intenso do ciclo da borracha. Os japoneses fizeram-se lojistas, técnicos, advogados e médicos; alemães, suíços e italianos tornaram-se proprietários de terras e barões da exploração de madeira, e hoje estão encastelados em suas mansões, sendo raramente vistos na cidade, a não ser por detrás das janelas de seus carrões. A vinda de migrantes das regiões andina e sub-andina não tem caráter tão permanente, pois os comerciantes vêm e vão, aproveitando-se das vantagens financeiras de se comerciar mercadorias locais a preços inflacionados nesta região relativamente remota. Finalmente, uma grande parte da população - também proveniente do "interior" (os Andes) — é formada por militares, uma vez que Riberalta conta com uma base naval, um regimento de infantaria e uma base aérea (embora a pista de pouso e decolagem seja pouco mais do que um terreno lamacento), e a pesada presença militar instiga ainda mais o temor dos Ese Ejja com relação à cidade. Os únicos com quem eles realmente têm contato e interação são os comerciantes do mercado, mas mesmo esses encontros são minimizados ao extremo.

Quando os Ese Ejja chegam a Riberalta, atracam o barco à margem do rio, longe do porto oficial. Os que trazem bananas, cana-de-açúcar e, ocasionalmente, mamão e grapefruits, vão ao mercado à procura de um comprador, que adquire todo o lote por um preço baixo. Alguns vendem diretamente aos transeuntes as frutas trazidas, amontoando-as na calçada da movimentada rua que passa ao longo do mercado. Nos meses da estação seca, montam-se acampamentos nas margens do rio, constroem-se abrigos com ramos de árvores e sobras de metal, com teto de lona, tapetes e esteiras de palha. A cobertura chega até o chão, deixando abertas as extremidades da barraca; do lado de fora, acendem-se fogueiras para cozinhar. Durante a maior parte do dia, há pessoas no interior dos abrigos. As mulheres sentam e conversam, cuidam dos bebês, terminam de tecer as esteiras que trouxeram para vender, esperam que os homens retornem de seus afazeres. Quando estão prontas para vender as esteiras, vagueiam, em grupos de três ou quatro, pela única parte da cidade que lhes é familiar: o mercado.

$\mathrm{Na}$ cidade, os Ese Ejja destacam-se por serem mais baixos do que a média, e por terem pele, cabelos e olhos mais claros. Geralmente, mulhe- 
res e crianças ficam descalças, suas roupas são velhas e manchadas. As mulheres carregam crianças de colo amarradas ao lado do corpo e não em carrinhos de bebê. Andam devagar e com cautela, em fila indiana, como fazem na floresta, passando por vezes as mãos nas paredes de tijolo enquanto andam; é seu comportamento, mais do que tudo, que chama a atenção, reforçando os preconceitos das pessoas da cidade. Elas andam cautelosamente; ficam paradas nas esquinas olhando a azáfama ao redor, como se não fizessem parte de tudo aquilo. Sussurram entre si comentários em ese ejja, olham para dentro das casas, especialmente se há uma televisão ligada, e observam fixamente. Elas não falam com quase ninguém, porque ficam constrangidas, queabicho; temem ser ridicularizadas e molestadas. Certo dia, acompanhei minha amiga Bajjima ao hospital, para uma ultrassonografia pré-natal. Em Portachuelo, ela geralmente falava comigo em espanhol - havia freqüentado a escola e era a mais falante entre as mulheres jovens - mas diante do médico e da enfermeira ela sequer pronunciou uma palavra, deixando que eu falasse em seu lugar.

Em suma, os Ese Ejja evitam contatos prolongados com os não-Ese Ejja. Imitam-nos no modo de vestir, no futebol, na música, na alimentação, mas preferem observá-los à distância. Observar de fora parece uma boa metáfora para a atitude dos Ese Ejja em relação aos bolivianos: são atraídos por estes últimos, mas não querem aproximar-se excessivamente, por medo de serem lesados. Essa atitude ficava evidente cada vez que os Tacana ou os professores da escola davam festas em Portachuelo. Nessas ocasiões, adultos e crianças reuniam-se do lado de fora da casa onde a festa se realizava e olhavam durante a noite inteira pelas frestas das paredes de adobe. Quando tratava-se de uma festa dos professores, os professores Ese Ejja também participavam, arrastando consigo suas relutantes esposas; mas as mulheres, tão logo podiam, saíam para juntar-se à multidão dos que observavam.

\section{Evitação estratégica de confronto}

As descrições precedentes ilustram a relação com os bolivianos, caracterizada por uma mistura de medo, vergonha e desejo de emulação, ou antes, desejo de serem bolivianos nos próprios termos ese ejja. O medo é o sentimento característico de todas as relações exteriores ao grupo dos parentes mais próximos, pois os de fora são sempre vistos como potencialmente perigosos. Como já tive oportunidade de mostrar (Lepri 2003), o mundo dos Ese Ejja é cheio de perigos visíveis e invisíveis, e há medidas a serem tomadas para evitá-los. Tais perigos são trazidos por inimigos, por não- 
parentes, por outros povos indígenas, por bolivianos e por espíritos, que estão sempre tentando prejudicar a pessoa - seja por pura cobiça, por inveja ou por vingança. A principal estratégia ese ejja para lidar com esses perigos é evitar a confrontação direta, subtraindo-se à raiva e à inveja de um inimigo. Durante minha permanência, os homens raramente brigaram, a não ser quando estavam bêbados (as mulheres nunca brigavam), e as pessoas em geral preferiam não se insultar diretamente, limitando-se a fazê-lo por intermédio de mexericos ${ }^{3}$. Idealmente, as acusações cara-acara eram evitadas, dando-se preferência a fazê-las por vias indiretas; quando havia suspeita de feitiçaria, não se falava abertamente: havia comentários e, após algum tempo, ou bem os rumores cessavam, ou, em casos extremos, uma das partes envolvidas acabava deixando a aldeia.

No que diz respeito aos espíritos, as pessoas tentam não irritá-los, respeitando, para isso, o comportamento adequado com relação ao consumo de alimentos e ao sexo, e vão longe no esforço de não lhes atrair a atenção. As crianças são especialmente vulneráveis aos ataques dos espíritos; sendo assim, ninguém dá qualquer atenção ao recém-nascido e mesmo a mãe finge com ele não se importar, pois os espíritos tentariam roubá-lo se pensassem que é precioso.

A evitação em relação aos bolivianos toma forma similar na ostentação estratégica da autodepreciação - no caso, os Ese Ejja apresentam-se a si próprios como fracos e sem valor. Certo dia, eu visitava uma amiga, casada com um professor de escola bilíngüe e com mais posses do que a maioria dos demais Ese Ejja. Um professor boliviano chegou e, do lado de fora, pediulhe um pouco de sabão. Minha amiga, até então loquaz, respondeu-lhe em voz baixa e lamentosa: "Não professor! Sou uma pobre pobre índia, não tem nada", chegando a distorcer sua expressão em espanhol, língua que domina consideravelmente. A posição que ela escolheu foi literalmente bem recompensada, já que o professor foi embora sem mais insistir.

Deve-se notar que não é necessário que tal autodepreciação seja inteiramente consciente, nem é ela acionada apenas na presença de Outros considerados perigosos; ao contrário, ela é internalizada a ponto de se tornar parte dos hábitos da pessoa e do sentido de self. Isto me foi sugerido durante reuniões da aldeia nas quais não havia presença de estrangeiros (exceto a minha), quando ouvi os homens afirmarem que não poderiam sair e colher castanhas-do-pará porque eram covardes e tinham medo de serem mortos pelos bolivianos. Conforme explicou um jovem, "se você for à floresta e encontrar um dejja, você deve deixar tudo o que conseguiu e se esconder, se não ele mata você". De fato, poucos Ese Ejja dedicam-se a essa atividade. Além disso, as pessoas recusam-se a ter qualquer posição oficial como re- 
presentantes externos da comunidade, alegando que não falam espanhol e que têm medo de sair para encontros ou reuniões na cidade e serem mortos. É também por essa mesma razão que se recusam a participar da política indígena (ver Lepri 2005a). Uma única vez, ouvi uma mulher dizer — literalmente - que costumava usar roupas esfarrapadas quando ia ao mercado para que os vendedores tivessem pena dela e lhe dessem comida de graça; mas em geral as pessoas não empregam essa estratégia de modo frio e calculado. Na maior parte do tempo, eu tinha a impressão de que eles haviam assimilado o discurso de sua própria inferioridade, como fica claro na caracterização que eles mesmos traçam a respeito dos dejja.

Porém, embora essas não sejam possivelmente escolhas inteiramente conscientes, os exemplos trazidos sugerem que, quando os Ese Ejja a partir de elementos tomados do discurso dominante na região - se apresentam diante dos bolivianos como preguiçosos, sujos, ignorantes, pobres e covardes, fazem-no para evitar qualquer interação. Assim, podem permanecer às margens da sociedade boliviana e não ter parte em relações perigosas. Em outras palavras, o discurso de seu próprio atraso e rudeza, embora os coloque em uma posição inferior, lhes é também bastante conveniente. Há, no entanto, uma dimensão suplementar da atitude ese ejja perante os bolivianos, da qual passarei a tratar a partir de agora.

\section{O tornar-se outro como processo histórico}

Nesta seção, sugiro uma comparação entre a noção ese ejja de "tornar-se dejja" e o processo sociocosmológico de tornar-se outro, discutido por Viveiros de Castro (1992:1 [1986:22]), para indicar similaridades lógicas subjacentes e sua coerência com o sentido de história que têm os Ese Ejja.

Viveiros de Castro sustenta que as sociedades tupi-guarani experimentam uma tensão para fora, para o Outro, que pode ser entendida como uma meta ou um destino. Essa "paixão pela exterioridade" (1992:3 [1986:26]) caracteriza sociedades sem centro, como, por exemplo, os Araweté do Brasil Central. A ausência de um centro contrasta com outros padrões encontrados em diferentes tipos de sociedades das terras baixas sul-americanas. Sociedades como as dos Gê e Bororo são consideradas dialéticas, porque a alteridade é interna ao complexo sistema de oposições complementares que caracteriza sua organização. Em vez disso, sociedades "minimalistas" (1992:6 [1986:32]) como a dos Araweté, desenfatizam as diferenças internas e as projetam para fora de seus limites; aspiram abarcar a alteridade, 
em um "esforço de superação dos limites externos do sistema, para recuperar as diferenças que foram extrojetadas" (1992:11 [1986:46]).

O processo do tornar-se outro fica evidente entre os Araweté que, segundo Viveiros de Castro, consideram-se crianças em relação aos maï, os deuses canibais celestes, a quem vêem como adultos. Essa relação é descrita explicitamente no mito, de acordo com o qual os Araweté, no início, viviam na terra junto com os maï, tendo estes, porém, deixado os Araweté para trás e se retirado para o céu, após um incidente entre uma mulher e um deus. Hoje, eles falam em alcançar sua plena realização pela morte e consumo canibalístico pelos maï, que tornam-se então seus esposos. Viveiros de Castro explica essa tensão para o exterior como um processo por intermédio do qual a sociedade se realiza.

Poder-se-ia objetar que o autor supervaloriza o aspecto sobrenatural da sociologia araweté, em detrimento do mundano; mas, como ele assinala, os Araweté não estão especialmente interessados em Outros do mundo dos vivos, concernidos que estão com os mortos e os deuses. No entanto, ele também sublinha que a mesma lógica antropofágica de incorporação do Outro é observável na atitude deles em relação ao antropólogo e nas tentativas de torná-lo um deles, fazê-lo "virar Araweté", bem como em seu "mimetismo agressivo" dos trabalhadores da Funai (1992:20 [1986:73-74, 76]). Isso é exemplificado pelo modo como o posto da Funai se tornou o centro da aldeia e assim, o que estava fora se torna o centro e "a aldeia Araweté torna-se, assim, função do Posto" (1992:21 [1986:75]). Esse é outro sinal de um traço geral das sociedades Tupi-Guarani, que necessitam do exterior para "se constituírem e se moverem" (1992:22 [1986:76]). A atitude araweté evoca significativamente a realidade dos Ese Ejja, assim como a de muitas outras sociedades amazônicas descritas na literatura e das quais se afirma necessitarem de estrangeiros para afirmarem sua identidade (ver, por exemplo, Erikson 1986).

Para os Ese Ejja, tornar-se o inimigo-Outro não se realiza através da morte e canibalismo, mas no processo da civilização, no qual os bolivianos têm um papel central. Conforme mencionei, esse processo em que eles aprendem a falar, vestir e comer como dejja - é um fenômeno histórico em curso, que coincide com um movimento rio abaixo, para longe da floresta - onde dizem que os "selvagens" ainda vivem - e na direção das cidades. Já discuti esse processo extensamente alhures (Lepri 2005a); aqui, bastará dizer que, na percepção que têm os Ese Ejja de estarem na história, o tempo e o espaço se fundem, e as distâncias no espaço e no tempo acabam por coincidir: as pessoas de antigamente viviam longe, rio acima, e foram deixadas para trás, tanto 
espacial quanto temporalmente. Sempre que os Ese Ejja falam das pessoas de antigamente, localizam-nas yahuajo, 'antes', mas também biacua, 'rio acima'. O passado é alhures, longe; o agora, por outro lado, é aqui, em Portachuelo, entre a selvageria da floresta e a civilização rio abaixo, na cidade. É relevante que a direção rio acima e a selvageria estejam associadas a um tempo de guerra constante - com outros povos indígenas e com os bolivianos. O movimento rio abaixo e orientado para o modo sedentário coincide com o fim da violência e o início da vida pacífica. Os Ese Ejja dizem que foram "civilizados" pelos dejja, que os "domesticaram" ehuonejji, que também significa 'criar, educar uma criança' (ver Alexiades 1999:158). Nesse sentido, os Ese Ejja, assim como os Araweté, estão submetidos a uma atração similar à "dinâmica centrífuga" descrita por Viveiros de Castro (1992:3 [1986:26]), em função da qual a tensão não se orienta para a preservação do grupo ou para a reprodução de relações e costumes em curso, mas para a transformação em algo outro, fora das fronteiras do grupo. Assim, os bolivianos, ao mesmo tempo temidos e evitados, são também referidos como o destino dos Ese Ejja - por exemplo, quando os jovens são descritos como "quase dejja".

\section{Conclusão}

Neste artigo, discuti o modo como os Ese Ejja constroem sua identidade na relação com os bolivianos. Essa relação e as atitudes que a acompanham são interessantes, por contradizerem a atitude aparentemente etnocêntrica de muitos povos amazônicos descritos na literatura antropológica. Elas também oferecem uma chave para o entendimento das conceitualizações ese ejja a respeito de alteridade e transformação.

Mostrei que as afirmações indígenas sobre "humanidade" são passíveis de erros de interpretação e que as fronteiras a que se referem não devem ser tomadas como rígidas e imutáveis. Portanto, em minha discussão, enfatizei a natureza relacional da identidade própria. Ao descrever a posição dos Bororo perante o Estado brasileiro, os Xavante e os missionários salesianos, Caiuby Novaes sustenta que a auto-imagem de um indivíduo ou da sociedade se modifica ao entrar em contato com outros. Esse é um ponto de partida valioso para explicar o problema aqui tratado, pois, dessa perspectiva, as diferentes atitudes observadas entre os Ese Ejja deixam de apresentar-se como contraditórias. A metáfora do "jogo de espelhos" é uma boa ferramenta para compreender a realidade multifacetada das relações interétnicas dentro do contexto amazônico e para além dele. 
Neste trabalho, concentrei-me nas relações dos Ese Ejja com os bolivianos e, parcialmente, com os Tacana, embora vários outros "espelhos" pudessem ser levados em consideração: "índios selvagens" reais ou imaginários, que projetam de volta uma imagem dos "ancestrais selvagens"; os missionários, em cuja presença os Ese Ejja se tornam bons cristãos evangélicos; e simpatizantes estrangeiros, como antropólogos e ativistas políticos que, em maior ou menor grau, os apresentam como habitantes de direito da região, que como tais devem ser defendidos e cujos costumes são valiosos. A multiplicidade de imagens produzidas nesse "jogo de espelhos" constitui a gama de papéis disponíveis para os Ese Ejja na negociação de sua posição no mundo. Essa metáfora oferece um modo interessante de se pensar sobre identidade/auto-imagem em geral, e de se explicar posições aparentemente contraditórias assumidas pelo mesmo indivíduo - neste caso, as atitudes ambíguas dos Ese Ejja com respeito aos dejja.

Recebido em 13 de maio de 2004

Aprovado em $1^{\text {o. }}$ de agosto de 2005

Tradução de Amir Geiger

Isabella Lepri é pesquisadora visitante associada ao Departamento de Antropologia da London School of Economics. E-mail: < i.lepri@lse.ac.uk>

\section{Notas}

* Este artigo é baseado em dezoito meses de trabalho de campo na aldeia ese ejja de Portachuelo, na margem esquerda do rio Beni, na Bolívia setentrional - entre novembro de 1999 e abril de 2001. A pesquisa foi financiada por uma bolsa de pósgraduação ESRC. Agradeço a todos os que leram, ouviram e comentaram diferentes versões do trabalho. Agradecimentos especiais vão para Edward Simpson, Henrietta Moore e Peter Gow; para o seminário de pesquisa da LSE, para o seminário do CIASE em St. Andrews e para o/a parecerista anônimo de Mana.

${ }^{1}$ Essa noção é coerente com o modelo "rizômico" de identidade, "ilimitado e expansivo", discutido por Dan Rosengren (2003). 
${ }^{2}$ Essa era a distribuição na época de minha primeira visita. No entanto, entre 2002 e 2003, a maioria dos residentes de Portachuelo Alto começou a migrar para um novo núcleo, chamado Chiquia, junto ao rio Madre de Dios.

${ }^{3}$ Durante minha primeira temporada, Portachuelo parecia estar passando por um período de zelo evangélico, e as pessoas evitavam beber abertamente. No entanto, várias vezes ouvi contarem sobre amplas brigas ocorridas nos anos anteriores, atiçadas em grande parte pelo álcool. Nessas ocasiões, as mulheres costumavam intervir para defender seus maridos.

\section{Referências bibliográficas}

ALEXIADES, Miguel N. 1999. Ethnobotany of the Ese Ejja: plants, health and change in an amazonian society. Doctoral Thesis, City University of New York.

CAIUBY NOVAES, Sylvia. 1997. The play of mirrors. The representation of self mirrored in the other. Austin: University of Texas Press.

ERIKSON, Philippe. 1986. "Altérité, tatouage et anthropophagie chez les Pano: la belliqueuse quête de soi". Journal de la Société des Americanistes, 72:185-209.

GOW, Peter. 1991. Of mixed blood. Kinship and history in peruvian Amazonia. Oxford: Clarendon Press.

GRAY, Andrew. 1996. Mythology, spirituality and history. The Arakmbut of amazonian Peru. Providence and Oxford: Berghahn Books.

HUGH-JONES, Stephen. 1978. The palm and the pleiades. Initiation and cosmology in northwest Amazonia. Cambridge: Cambridge University Press.

LEPRI, Isabella. 2003. 'We are not the true people'. Notions of identity and otherness among the Ese Ejja of northern Bolivia. Doctoral Thesis, University of London.
. 2005a. "La politique indigéniste vue par une ethnie amazonienne". Lazos. Bulletin de liaison bolivianiste, 7:125-132. 2005b. "The meanings of kinship among the Ese Ejja of northern Bolivia". Journal of the Royal Anthropological Institute, 11(4):703-723.

LÉVI-STRAUSS, Claude. 1977. Structural anthropology II. London: Allen Lane [Edição brasileira: Antropologia estrutural II. Rio de Janeiro: Tempo Brasileiro, 1976. Tradução de C. S. Katz].

MCCALLUM, Cecilia. 1990. "Language, kinship and politics in Amazonia". Man, 25(3):412-433. 1997. "Comendo com Txai, comendo como Txai. A sexualização das relações étnicas na Amazônia contemporânea". Revista de Antropologia, 40(1):109-147.

PELUSO, Daniela M. 2003. Ese Ejja epona: woman's social power in multiple and hybrid worlds. Doctoral Thesis, Columbia University.

ROSENGREN, Dan. 2003. "The collective self and the ethnopolitical movement: 'rhizomes' and 'taproots' in the Amazon". Identities: global studies of culture and power, 10:221-240. 
SEEGER, Anthony; DA MATTA, Roberto e VIVEIROS DE CASTRO, Eduardo. 1979. "A construção da pessoa nas sociedades indígenas brasileiras". Boletim do Museu Nacional, 32:2-19.

SISKIND, Janet. 1973. To hunt in the morning. New York: Oxford University Press.

SÖKEFELD, Martin. 1999. "Debating self, identity, and culture in anthropology". Current Anthropology, 40(4):417-447.

TAYLOR, Anne-Christine. no prelo. "Sick of history. Contrasting regimes of historicity in the upper Amazon". In: C. Fausto e M. J. Heckenberger (eds.), When time matters: history, memory and identity in Amazonia.

TOWNSLEY, Graham. 1987. "The outside overwhelms. Yaminahua dual organisation and its decline". In: H. O. Skar e F. Salomon (eds.), Natives and neighbours in South America. Anthropological essays. Göteborg: Etnografiska Museum. pp. 355-376.

TURNER, Terence 1993. "De cosmologia a história. Residência, adaptação e consciência social entre os Kayapó". In: E. Viveiros de Castro e M. Carneiro da Cunha (orgs.), Amazônia. Etnologia e história indígena. São Paulo: Núcleo de História Indígena e do Indigenismo da USP/ FAPESP. pp.43-66.

VIVEIROS DE CASTRO, Eduardo. 1998. "Cosmological deixis and amerindian perspectivism". Journal of the Royal Anthropological Institute, 4(3):469-88. [Versão original: "Os pronomes cosmológicos e o perspectivismo ameríndio". Mana. Estudos de Antropologia Social, 2(2):115-143, outubro 1996]. . 1992. From the enemy's point of view. Humanity and divinity in an amazonian society. Chicago and London: The University of Chicago Press [Tradução com modificações de Araweté - os deuses canibais. Rio de Janeiro: Jorge Zahar Editor/Anpocs, 1986]. 


\section{Resumo}

Este artigo explora a construção da identidade própria, que se dá na relação com os outros, em uma sociedade da Amazônia boliviana. Ele tem como foco as atitudes ambíguas dos Ese Ejja em relação aos bolivianos (não-indígenas). Sustento que a ambivalência dos Ese Ejja reflete a natureza mutável, contextual e relacional da identidade, entendida como auto-imagem. A relação descrita é caracterizada pela autodepreciação dos Ese Ejja, parcialmente atribuível a fatores históricos, econômicos e políticos, mas também coerente com a estratégia indígena de evitar confrontação direta com entidades perigosas. Além disso, sugiro que essa postura em relação aos estranhos poderosos também pode ser lida segundo as noções sociocosmológicas indígenas relativas à alteridade e ao tornar-se outro, e a partir do sentido que têm os próprios Ese Ejja de estarem na história

Palavras-chave: Amazônia, Bolívia, Povos indígenas, Auto-imagem, Identidade, Alteridade

\section{Abstract}

This paper explores the construction of self-identity in relation to others in a Bolivian Amazon society, through the lens of the ambivalent attitudes of the Ese Ejja towards non-indigenous Bolivians. I argue that the Ese Ejja's ambivalence reflects the mutable, contextual and relational nature of identity, understood as selfimage. The relationship described here is characterised by self-debasement on the part of the Ese Ejja. This is partly attributable to historical, economic and political factors, but is also consistent with the indigenous strategy of avoiding direct confrontation with dangerous entities. Moreover, it is suggested that this stance towards powerful foreigners can also be read in terms of indigenous socio-cosmological notions of otherness and of Otherbecoming and of the Ese Ejja's own sense of being in history

Key words: Amazonia, Bolivia, Indigenous people, Self-image, Identity, Alterity 